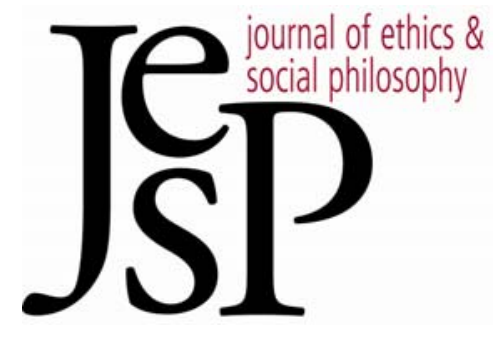

\title{
TwO APPROACHES TO INSTRUMENTAL RATIONALITY AND BELIEF CONSISTENCY
}

BY JOHN BRUNERO

Journal of Ethics \& SOCIAL PhiLOSOPHY

VOL. 1, NO. $1 \mid$ APRIL 2005 URL: WWW.JESP.ORG 
$\mathrm{I}$ N SPEAKING OF INSTRUMENTAL RATIONALITY, philosophers usually have in mind the rational requirement of taking the necessary means to our ends. A central question of this paper is how this rational requirement is related to the rational requirement to hold consistent beliefs. I will primarily be concerned with evaluating two ways of understanding the relationship between instrumental rationality and belief consistency. First, I will consider R. Jay Wallace's view that instrumental rationality just consists in having consistent beliefs. ${ }^{1}$ According to this view, if you are an instrumentally irrational agent, you have a set of inconsistent beliefs. Wallace thinks that this allows for the normativity of instrumental rationality to be traced to the independent rational requirement to hold consistent beliefs. Second, I will consider the view, proposed by John Broome, that the requirements of instrumental rationality and belief consistency are similar in structure. ${ }^{2}$ Broome does not attempt to reduce instrumental rationality to belief consistency, but suggests that the two are structurally similar in that the correctness of both instrumental reasoning and reasoning leading to consistent beliefs is explained by appealing to the logical relations of propositions that are either intended or believed. Despite the differences, both Broome and Wallace do share some common assumptions in that they both aim to provide an account of instrumental rationality according to which instrumental rationality involves a restriction on a certain combination of attitudes - for Broome, a certain combination of intentions (along with a belief about the necessary means) and, for Wallace, a certain combination of beliefs.

I argue that Broome's approach is preferable to Wallace's since there are three objections to Wallace's account, which I present in the first section below, that Broome can avoid. I believe it is better to think of instrumental rationality as involving a restriction on a certain combination of intentions than a restriction on a certain combination of beliefs.

However, in the second section, I go on to note that Broome's account is problematic since it does not seem to be the case that having consistent intentions suffices to make an agent instrumentally rational. I argue that an agent with consistent intentions could still be instrumentally irrational by failing in his instrumental reasoning. So, if we say that instrumental rationality consists in having consistent intentions, then we haven't told the whole story of instrumental rationality. In the third section, I aim to show that this is an important conclusion because it shows that Broome's conception of instrumental rationality as a restriction on a certain combination of intentions is actually vulnerable to a critique which both he and Wallace present against different parts of Christine Korsgaard's conception of instrumental rational- 
ity. Both Broome and Wallace point to certain instances in which an agent can engage in instrumental reasoning (correctly or incorrectly) and suggest that Korsgaard's account needs to be expanded to accommodate these instances of instrumental reasoning. But I point out that it is possible for an agent to engage in instrumental reasoning (correctly or incorrectly) even when his intentions are consistent. So, by the same reasoning which Broome and Wallace use against Korsgaard, Broome's account of instrumental rationality needs to be expanded to accommodate these instances of instrumental reasoning.

In short, I argue that while it is better to think of instrumental rationality as involving a requirement to hold consistent intentions than a requirement to hold consistent beliefs, we should not think that such a requirement explains the whole of instrumental rationality.

\section{Instrumental Rationality as Belief Consistency}

On Wallace's view, the normative force of instrumental rationality is accounted for in terms of the inconsistency of the beliefs held by the instrumentally irrational agent. Specifically, if you are an instrumentally irrational agent - that is, if you intend to $\mathrm{X}$, believe $\mathrm{Y}$ to be a necessary means to $\mathrm{X}$, yet fail to intend to $\mathrm{Y}-$ you will hold the following inconsistent set of beliefs:

(1) It is possible that you do X.

(2) It is possible that you do X only if you also intend to do Y.

(3) You do not intend to do Y.

Wallace notes that "the incoherence of these beliefs is a straightforward function of the logical relations among their contents, suggesting that the normative force of the instrumental principle can be traced to independent rational constraints on your beliefs - in particular constraints on certain combinations of beliefs.",3

Why would the agent believe (1)? Wallace claims that a person can intend to do X only if he believes that it is possible for him to do X. Wallace notes that this marks a difference between intentions and desires since we do not specify a similar necessary condition for desires. You could have desires for things that you believe to be impossible given the way the world is, such as (Wallace's example) a desire for the immediate end to global warming. You can want this, but this is not something you can intend. As for (2), Wallace claims that instrumental reasoning will involve some belief about what is necessary to ensure the possibility of $\mathrm{X}$ - specifically, you will believe that in order for your doing $\mathrm{X}$ to be possible, you need to intend to take the means to that end. However, an agent who does not intend to take the means, pro- 
vided that he is "minimally self-aware," will also believe (3) - that he does not intend to take the means. ${ }^{4}$

Note that none of the beliefs (1)-(3) are beliefs about instrumental rationality or its authority. It is not that the agent has some belief about what instrumental rationality requires of him and sees his own behavior as inconsistent with this requirement. Rather, the instrumentally irrational agent will have inconsistent beliefs about ordinary matters of fact. In Wallace's view, this allows for the normativity of instrumental rationality to be accounted for in terms of the requirement to have consistent beliefs.

One worry about Wallace's account is that we lose our grip on the fact that instrumental reasoning is practical in the following basic sense: it tells us what to intend, not just what to believe. On Wallace's account, someone could come to escape instrumental irrationality by ceasing to believe that he does not intend the means. But surely instrumental rationality requires more than this. It requires that he actually intend the means. Let's call this the "practicality problem." Wallace is aware of this difficulty and argues that it is not a serious problem. He proceeds by considering potential counterexamples: someone who, wishfully or carelessly, comes to believe he intends the means when he actually doesn't and someone who actually does intend the means but doesn't believe that he does. Wallace's strategy of reply is to argue that ordinarily our intentions and our beliefs about what we intend do not diverge in this manner. ${ }^{5}$ But even if he is right about this, it would not solve the practicality problem for the following reason: beliefs aim to represent the world the way it really is. So, our beliefs about our intentions aim to represent what it is that we really intend. But if we are required to revise our intentions because we are required to revise our beliefs about them, then our beliefs would no longer be aiming to represent what it is that we really intend. Suppose you see that you have the set of inconsistent beliefs (1), (2), and (3) and come to revise (3) by instead believing that you intend the means and then you come to actually intend the means. Your new belief (that you intend the means) is not aiming to represent the world the way it really is and, therefore, cannot qualify as genuine belief. At least in the normal case, I must first revise my intentions before revising my beliefs about them; my beliefs about my intentions will change in order to track my revisions in intentions, and not vice versa. But, if this is the case, there must be some independent grounding for the requirement to first revise my intentions. Thus, the normativity of belief consistency would not be doing the primary work in accounting for the normativity of instrumental rationality.

A second worry about Wallace's account concerns the use of the word 'possible' in (1) and in the antecedent of (2). Consider the agent who chooses to escape irrationality by revising the belief (1) and coming to believe that his doing $\mathrm{X}$ is impossible. In so revising, the agent would come to have consistent beliefs. But it seems rather inauthentic for the agent who abandons an 
end to claim that the object of that end was impossible. For example, suppose I believe I do not intend to study and I believe it is possible to pass the test only if I also intend to study, and I believe it is possible to pass the test thereby giving me a set of inconsistent beliefs - and I come to revise my beliefs by believing it impossible to pass the test. In believing passing the test to be impossible, it sounds like I am being inauthentic - that is, it sounds like I am believing passing the test to be something outside of my control when it really is within my control. The reason this sounds so inauthentic is that there is still a sense in which passing the test is possible: I can sit down and study and pass the test. It is not that passing the test ceases to be an option just because I do not intend the means of studying. Passing the test is not impossible in the same sense in which immediately ending global warming is impossible - that's just simply not an option since it is outside of our control.

Perhaps we could distinguish between two senses of 'possible.' On the wide sense of 'possible', something is possible in the sense that it is an option for our deliberation. Some things are not options for us, like immediately ending global warming, and are therefore considered impossible. On the narrow sense of 'possible', something is possible in the sense that it can be brought about given our other intentions. Passing the test is possible given that I intend to study, but becomes impossible if I do not intend to study. Of course, passing the test is still an option for us - it is just that in order to do it, we need to intend the means of studying.

The narrow sense of 'possible', though peculiar, is not problematic in itself. What is problematic is that with this sense of 'possible', it is unclear how Wallace can be justified in thinking that an agent who intends an end also has the belief (1). It seems false to think that one can intend $\mathrm{X}$ only if one believes that $\mathrm{X}$ is possible (in the narrow sense of what can be brought about given our other intentions). It often happens that we are aware of our own instrumental irrationality. We do not intend the means to our ends and we are aware of this and so we believe the end to be impossible (in the narrow sense). We believe the end cannot be brought about given our other intentions. Sure, we would be irrational, but it is certainly possible for us to intend some end and believe that it cannot be brought about given our other intentions. As long as we can be instrumentally irrational, we can intend the 'impossible' in the narrow sense.

Perhaps Wallace could claim that insofar as one is instrumentally rational, one intends to do $\mathrm{X}$ only if one believes $\mathrm{X}$ is possible. But now it is no longer the case that "the normative force of the instrumental principle can be traced to independent rational constraints on your beliefs" since the instrumental principle is used to explain why we rationally must be committed to a belief in the possibility of doing $\mathrm{X}$ given our intention to do $\mathrm{X}$. The belief in the possibility of doing $\mathrm{X}$ is not a necessary component of our having $\mathrm{X}$ as an end, but something to which we need to be rationally committed given that we have $\mathrm{X}$ as 
an end. And instrumental rationality will be brought in to explain that very commitment.

The idea that intending an end involves a belief in the end's possibility gains its plausibility from the wide sense of 'possible.' We cannot intend things we believe are not options for us, like immediately ending global warming. But the idea seems implausible on the narrow sense of 'possible' since we can, when we are irrational, intend things that we believe can not be brought about given our other intentions.

A third worry about Wallace's account is that though it can make sense of how instrumental rationality is concerned with consistency in intentions, it cannot make sense of how instrumental rationality is concerned with meansends coherence. One version of the distinction between consistency in intentions and means-ends coherence is put forth by Michael Bratman. ${ }^{6}$ According to Bratman, my intentions are consistent just when my plans fit together with my beliefs into a consistent conception of the future. Means-ends coherence goes beyond consistency in that it requires us to form plans about how to achieve our ends. The difference between consistency and coherence can be seen by considering the case of someone who fails to intend the necessary means to her ends and also fails to notice this. Alice intends to pass the test, knows that a necessary means is to study, and fails to intend to study, but does not notice that she fails to intend to study. It just slips her mind entirely. Her intentions and beliefs may well fit together into a consistent conception of the future, so she would be consistent, but she is still subject to criticism insofar as she is incoherent. As Bratman puts it, "I do not get off the hook of means-ends incoherence just by not noting the lacuna in my plans." 7

Wallace, in attempting to account for instrumental rationality in terms of the inconsistent beliefs held by the instrumentally irrational agent, claims that the instrumentally irrational agent, being "minimally self-aware," will believe that he does not intend to Y. While it is plausible to claim that an agent who intends not to $Y$ will believe that he does not intend to $Y$, it is not plausible to claim that someone who fails to intend to $Y$ has the belief that he does not intend to Y. Alice may fail to intend to study and fail to notice this; it just slips her mind. But if she does not hold the belief that she does not intend to study, then there is no way on Wallace's account to convict her of instrumental irrationality. Thus, Wallace's account cannot make sense of how instrumental rationality is concerned with means-ends coherence.

\section{Instrumental Rationality and Belief Consistency}

John Broome does not attempt to account for the normativity of instrumental rationality by pointing to an inconsistency in the beliefs held by the instrumentally irrational agent, as Wallace does. Rather than reduce instrumen- 
tal rationality to belief consistency, Broome notes that the two are structurally similar. The normativity of both instrumental rationality and belief consistency is explained in terms of the logical relations among the propositions which are intended in the former and believed in the latter. ${ }^{8}$

Broome states that both intentions and beliefs are propositional attitudes. While a belief involves "taking true" a certain proposition, an intention involves "setting to make true" a certain proposition. Taking "B" to mean "you believe that" and "I" to mean "you intend that" and supposing that you are some guy named Chris, Broome presents the following as an example of correct instrumental reasoning:

(4) I (Chris will buy a boat)

(5) B (For Chris to buy a boat a necessary means is for Chris to borrow money)

(6) I (Chris will borrow money). ${ }^{9}$

This is paralleled by an example of correct theoretical reasoning:

(7) B (Chris will buy a boat)

(8) B (For Chris to buy a boat a necessary means is for Chris to borrow money)

(9) B (Chris will borrow money). ${ }^{10}$

While this example of theoretical reasoning can easily be done by someone other than Chris, we could imagine Chris himself doing it if his financial transactions were in the hands of someone else.

Broome asks what it is that makes it the case that these are examples of correct reasoning. His answer is that the propositions involved - what is in the parentheses in both (4)-(6) and (7)-(9) - constitute a logically valid inference. If "Chris will buy a boat" and "For Chris to buy a boat a necessary means is for Chris to borrow money" are both true, then "Chris will borrow money" is true. That this inference is logically valid explains why it is that an agent cannot rationally intend to buy a boat and believe borrowing money is a necessary means without intending to borrow money. Likewise, that this inference is logically valid explains why it is that an agent cannot rationally believe Chris will buy a boat, believe borrowing money is necessary means and not believe Chris will borrow money. ${ }^{11}$ Broome notes that intentions involve "setting to make true" a proposition and beliefs involve "taking true" a proposition and this common concern for truth is what allows for the logical relations of the propositions to ground the correctness of the reasoning in (4)-(6) and (7)-(9).

Broome's account avoids the three problems with Wallace's account. First, the agent engaged in instrumental reasoning concludes by forming an intention directly, not by some indirect, circuitous route through his beliefs about what he intends. Second, there are no worries about the use of the 
term "possible" nor is there confusion about what is a necessary component of an intention versus what is rationally required given an intention. Third, the account captures both consistency and means-ends coherence since agents are required to intend the necessary means to their ends and they cannot escape from this requirement through ignorance of their failure to intend the necessary means.

On Broome's account, an agent who has the intention in (4) and the belief in (5) is required to actually intend the necessary means in order be instrumentally rational. However, one worry about Broome's account is that it does not seem to be the case that if this agent were to intend the necessary means, he would thereby be instrumentally rational; the formation of the intention in (6) is not sufficient for instrumental rationality. Suppose the intention in (6) is weak-willed. Suppose I see no reason to borrow money, perhaps because it would put me too far into debt, but intend to do so anyway. So, my intentions are consistent. But suppose that even though I see no reason to borrow money, I don't see that I have no reason to buy the boat. I fail to see the relevant inferential connections. On Broome's view, I would be instrumentally rational since my intentions are consistent. But this seems too quick. If I were instrumentally rational, I would see that since I have no reason to borrow, I have no reason to buy the boat. Correct instrumental reasoning would start from the premise that I have no reason to borrow the money, and conclude that I have no reason to buy the boat. And if I fail to see the relevant inferential connections here, it seems that I would be exhibiting a form of instrumental irrationality, even if my intentions are consistent. So, having consistent intentions does not suffice to make one instrumentally rational.

Instrumental reasoning involves seeing a certain inferential connection between means and ends. But one could fail to see the relevant inferential connections even when one's intentions are consistent. And it seems right to count this failure in reasoning as a form of instrumental irrationality. We'll return to this point again in the next section.

Is the formation of the intention in (6) even necessary to make an agent instrumentally rational? Perhaps not, if we are to draw a sharp divide between instrumental rationality and the rest of practical rationality. It seems that in order to qualify as instrumentally rational, I need only judge that (given that I intend the end of buying the boat) I am required to borrow the money. Of course, there is an additional requirement of practical rationality to form intentions in line with our judgments about what we should do, but this requirement does not seem to be part of instrumental rationality, strictly speaking, since conformity to this requirement need not involve the recognition of any means-ends relations; it could simply involve seeing that one has made a certain judgment about what one should do and forming an intention to do it. For example, if I intend to buy the boat, believe that borrowing is neces- 
sary to do this, but do not see myself as required to borrow, then I am instrumentally irrational. However, if I do see that I am required to borrow, but do not intend to borrow, then I am instrumentally rational but still practically irrational in the sense that I am weak-willed. So, on this line of thought, the formation of the intention in (6) is not necessary for instrumental rationality.

But, on the other hand, we shouldn't be concerned to draw a sharp line between instrumental rationality and the rest of practical rationality. After all, many of the stock examples of what is commonly considered instrumental irrationality do not involve an agent failing to draw instrumental inferential connections, but instead involve the more general shortcoming of agents failing to intend what they judge they should do. (It is a more general shortcoming in the sense that the same failure is found in cases in which agents set ends contrary to what they judge they should do.) To take one example, consider Korsgaard's case of Tex, who, unfortunately, must have his leg sawed off without anesthetic in order to save his life. ${ }^{12}$ The doctor asks Tex whether he wants to live and Tex replies in the affirmative and Tex understands that cutting off his leg is a necessary means to living, yet he has no intention of having the saw come anywhere near his leg. Korsgaard correctly notes that "The right thing to say is that fear is making Tex irrational. ... Faced with the prospect of having his leg sawed off, Tex's sensible nature is quite understandably in revolt." 13 In saying that Tex is being instrumentally irrational, Korsgaard is not saying that he failed to infer that he has reason to have his leg sawed off from his intention to live (or from the reasons for this intention) and his belief that the leg must be sawed off if he is to live. Tex does indeed draw this inference, but out of fear, revolts against his own judgment that his leg needs to be cut off. Many examples of what we commonly take to be instrumental irrationality are like this in that the agent's failure does not lie in his failure to understand the logical relations between his intentions and belief about the necessary means, but instead lie in the more general failure to form intentions in line with his judgments about what he should do.

In noting that instrumental irrationality may involve (a) failing to draw instrumental inferential connections or (b) the more general shortcoming of failing to intend to do as we judge that we should do, I am not noting a difference between instrumental rationality and belief consistency since agents could be irrational along both of these lines with beliefs. First, I could fail to draw the correct inferential connections and fail to see why belief in $\mathrm{P}$ and $\mathrm{P} \rightarrow \mathrm{Q}$ requires me to believe $\mathrm{Q}$. Perhaps I just failed to see the logical relations between $\mathrm{P}, \mathrm{P} \rightarrow \mathrm{Q}$ and $\mathrm{Q}$. (If you are worried that no person could fail to see such a connection, then consider a slightly more complicated logically valid relation: perhaps I believe $\mathrm{P} \rightarrow(\mathrm{R} \rightarrow(\mathrm{Q} \vee \mathrm{S})), \mathrm{P} \wedge \mathrm{R}, \mathrm{S} \rightarrow \mathrm{T}, \neg \mathrm{T} \vee \neg \mathrm{W}$, and $\mathrm{W}$, but do not see why I am required to believe Q.) Second, I could come to see that I am required to believe Q, yet fail to believe it. Perhaps I fail to have some of the dispositions necessary for a belief in Q even though 
I see myself as required to believe Q. T.M. Scanlon has argued that having a belief involves a complicated set of dispositions: "[A] person who believes that $\mathrm{P}$ will tend to have feelings of conviction about $\mathrm{P}$ when the question arises, will normally be prepared to affirm $\mathrm{P}$ and use it as a premise in further reasoning, will think of $\mathrm{P}$ as a piece of counterevidence when claims incompatible with it are advanced, as so on." "14 A person could see that they are required to believe Q but find themselves falling short of having some of these dispositions. Thus, paralleling instrumental irrationality, people could be irrational in (a) failing to see how they are required to believe Q given their beliefs in $\mathrm{P}$ and $\mathrm{P} \rightarrow \mathrm{Q}$ or (b) failing to believe as they judge that they should.

To sum up, for an agent with the intention in (4) and the belief in (5), the formation of the intention in (6) is not sufficient to make the agent instrumentally rational since he may have consistent intentions due to one of those intentions being weak-willed yet nonetheless still fail to see the relevant inferential connections between means and ends. And the formation of the intention in (6) would not be necessary to make the agent instrumentally rational if were to define instrumental rationality narrowly and separate it from the rest of practical rationality. But we need not present such a narrow definition of instrumental rationality. Doing so would be contrary to our ordinary thinking about instrumental rationality. We should instead simply note that one could fail to be instrumentally rational in two ways, through a failure in reasoning or through a more general failure in motivation. A similar analysis could be presented for theoretical rationality.

\section{Reasoning and Requirements}

Despite the differences in the accounts offered by Wallace and Broome, both do share something in common. Both are reacting against a view of instrumental rationality according to which an agent's intending an end gives him a reason to take the means to that end and against a view of belief consistency according to which an agent's believing a proposition gives him a reason to believe the logical consequences of that proposition. Both Wallace and Broome argue against the claim that intentions and beliefs are reason-giving in this sense. One argument against this claim is that beliefs logically entail themselves, so if having a belief gives you a reason to believe its logical consequences, having the belief that $\mathrm{P}$ gives you a reason to believe that $\mathrm{P}$. But this is an implausible view of normativity; beliefs are not self-justifying. Likewise, instrumental reasoning sometimes involves discovering what is constitutive of some end you have (say, discovering what constitutes an offensive act when one intends to perform an offensive act), so, if intentions are reasons, intending the end would give you a reason to intend what is constitutive of that end. ${ }^{15}$ Again, this is an implausible view of normativity; intentions cannot justify themselves. ${ }^{16}$ 
Both Wallace and Broome develop alternative accounts of instrumental rationality that avoid the conclusion that our intentions can "bootstrap" a reason into existence. ${ }^{17}$ Both suggest that we instead understand the normativity of instrumental rationality as a restriction on a certain combination of attitudes - for Broome a restriction on a certain combination of intentions (along with a belief about the necessary means) and for Wallace a restriction on a certain combination of beliefs. With this strategy, they argue, your intending an end does not give you a reason to intend the means.

The idea of a restriction on a certain combination of attitudes is further developed by Broome in his work on what he calls "normative requirements." Broome distinguishes between two different normative relations: the 'ought' relation and the 'requirement' relation. ${ }^{18}$ The requirement relation, unlike the ought relation, presents a restriction on a certain combinations of attitudes and this difference can be seen as a difference in logical structure. Take $p$ and $q$ to be propositions. For the ought relation, if $p$ is true, we ought to see to it that $q$. Formally, $\mathrm{p} \rightarrow \mathrm{Oq}$, where "O" stands for "you ought to see to it that" and " $\rightarrow$ " stands for the material conditional. For example, if John is drowning, we ought to see to it that he is rescued. For the requirement relation, however, normativity is attached to the relation between $p$ and $q$ and not to consequent, so we would formally represent this as $\mathrm{O}(\mathrm{p} \rightarrow \mathrm{q})$; we ought to see to it that if $p$ is true, so is $q$. Broome argues that the requirement to believe the logical consequences of one's beliefs and the requirement of instrumental rationality are both examples of normative requirements in this sense. ${ }^{19}$ These requirements can be satisfied in two ways. Concerning the former, one could come to believe the logical consequences of one's beliefs or one could abandon one's initial beliefs. Concerning the latter, one could intend the means to one's end or one could abandon the end. What is prohibited here are certain combinations of attitudes: having beliefs without believing their logical consequences and intending an end without intending the means.

Broome goes on to argue that the requirement relation does not entail that one ought to intend the means or even that one has a reason to intend the means, and, therefore, can avoid the problems of self-justifying intentions. ${ }^{20}$ Wallace endorses Broome's understanding of the requirement relation, but sees instrumental rationality as consisting in a normative requirement to hold consistent beliefs, not a normative requirement to hold consistent intentions.

The issue of whether intentions are reasons is a complicated one that I do not wish to address in this paper. I mention Broome's concept of normative requirement only because I want to consider the relationship between instrumental reasoning and the normative requirement to hold consistent intentions. Specifically, I want examine an argument used by both Broome and Wallace concerning instrumental reasoning that might be thought to support 
a conception of instrumental rationality according to which instrumental rationality involves a normative requirement to hold consistent intentions. The argument, which I'll explain below, is used by both Broome and Wallace against parts of Christine Korsgaard's account of instrumental rationality. Basically, Broome and Wallace point to instances of instrumental reasoning and then suggest that Korsgaard's account is inadequate because it does not accommodate these instances of instrumental reasoning. But I argue that an account of instrumental rationality as a normative requirement to hold consistent intentions is also vulnerable to this same line of criticism.

Broome uses the argument against Korsgaard's claim that "unless there are normative principles directing us to the adoption of certain ends, there can be no requirement to take the means to our ends." 21 Wallace uses the argument against Korsgaard's claim that "for the instrumental principle to provide you with a reason, you must think that the fact that you will an end is a reason for the end." 22 (Although Korsgaard thinks that there have to be normative principles directing us to the adoption of certain ends, she remains skeptical of realist accounts of these principles and instead thinks that the normative principles are provided by Kantian autonomous willing. Thus, we must think that the fact that we will an end is a reason for that end.) The argument, which I will call the "instrumental reasoning argument," appeals to the fact that agents can engage in (correct or incorrect) instrumental reasoning even when they are intending ends they have no reason to have and even when they are intending ends they think that they have no reason to have. Therefore, according to the argument, the right account of instrumental rationality cannot have it that the norms of instrumental rationality are applicable only to intentions we have reason to have or applicable only to intentions we think we have reason to have. It would be wrong to think that the norms of instrumental rationality are applicable only to intentions we have reason to have since agents can engage in instrumental reasoning (correctly or incorrectly) in pursuing some end they have no reason to pursue. It would be wrong to think that the norms of instrumental rationality are applicable only to intentions we think we have reason to have since agents can engage in instrumental reasoning (correctly or incorrectly) in pursuing some end they think they have no reason to pursue.

Broome presents a version of the instrumental reasoning argument against a particular claim made by Korsgaard. As I mentioned above, Korsgaard says that "unless there are normative principles directing us to the adoption of certain ends, there can be no requirement to take the means to that end." 23 As Broome reads it, Korsgaard is here making a claim about instrumental reasoning, specifically that "instrumental reasoning could transmit normativity from the end to the means but it cannot itself give the means normativity." 24 In other words, an agent must have a reason to intend the end if there is to be any normativity attached to intending the means. 
Broome's notion of normative requirement, in contrast, does not have it that there has to be a reason to intend the end; one only needs to intend some end for the requirement to intend the means to be in place. As Broome sees it, his approach has an advantage over Korsgaard's since it is better able to explain the fact that instrumental reasoning is possible in "unfavorable conditions," namely, conditions in which we have no reason to intend the end. Broome writes:

Korsgaard's mistake [of thinking that an agent must have a reason to intend an end if there is to be any normativity attached to intending the means] illustrates an important feature of normative requirements. Reasoning is possible even in conditions that are unfavorable in a particular way. In your reasoning, you can take as premises beliefs and intentions you have no reason to have, and even beliefs and intentions you ought not to have. The nature of your reasoning is unaffected by whether or not you ought to have the beliefs and intentions it is premised on. Instrumental reasoning brings you to take the appropriate means to your ends, and it is not paralysed if your ends happen to be ones you should not have..$^{25}$

If you think that there has to be a reason to pursue some end for normativity to attach to intending the means, then you are incapable of explaining how it is that instrumental reasoning is possible in unfavorable conditions. But if you understand instrumental rationality as a restriction on a certain combination of attitudes, a normative requirement in Broome's sense, then you are capable of explaining how instrumental reasoning is possible in unfavorable conditions. $^{26}$

Wallace presents a version of the instrumental reasoning argument against Korsgaard's claim that agents must think that their intending the end gives them reason to intend the means. Korsgaard writes:

[F]or the instrumental principle to provide you with a reason, you must think that the fact that you will an end is a reason for the end. It's not exactly that there has to be a further reason; it's just that you must take the act of you own will to be normative for you. And of course this cannot mean merely that you are going to pursue an end. It means that your willing an end in a sense makes it good. The instrumental principle can only be normative if we take ourselves to be capable of giving laws to ourselves - or, in Kant's own phrase, if we take our own wills to be legislative. ${ }^{27}$

In Korsgaard's view, willing an end involves setting up a law for oneself, a law which one can obey or disobey. She notes that her view involves thinking of the self as consisting of two parts: a governing part (the will) which sets the law and a part which is capable of resisting the will. She writes:

Then what does it mean to say I take the act of my own will to be normative? Who makes a law for whom? The answer in the case of the instrumen- 
tal principle is that I make a law for me. And this is a law which I am capable of obeying or disobeying. At this moment, now, I decide to work; at the next moment, at any moment, I will certainly resolve to stop. If I am to work, I must will it - I must resolve to stay on track. Timidity, idleness, and depression will exert their claims in turn, will attempt to control or overrule my will, to divert me from my work. ${ }^{28}$

However, a version of the instrumental reasoning argument can be brought in against Korsgaard's view. You can perfectly well reason from intentions that you think that you have no reason to have, and even that you think that you ought not to have. I happen to be remarkably effective in figuring out the means to procrastinate even though I do set for myself a law to do my work. When depression about my work exerts its claim and I decide to go the bar instead of working, I find myself remarkably good in reasoning about what's necessary to get there. In short, I can figure out how best to pursue those ends which do not emerge from the lawgiver part of the self. As Wallace puts the objection:

$[1] \mathrm{t}$ seems undeniable that agents can display a kind of instrumental rationality in the pursuit of ends that they do not themselves endorse, when for instance they are in the grip of akrasia. People sometimes exhibit great intelligence and skill in executing plans that they view as dubious and questionable - think, for instance, of the extraordinary talent many of us display at procrastinating when it comes to tasks we regard as worthy but difficult. It seems plausible to regard this kind of intelligence - cleverness, as we might call it - as a form of instrumental rationality, relative to the ends that we are in fact pursuing. ${ }^{29}$

Wallace goes on to develop this objection quite thoroughly against Korsgaard and then proceeds to argue that the Broomean approach of looking at instrumental rationality as involving a restriction on a certain combination of attitudes is able to adequately account for cases of "cleverness." 30 There is no need to go into the details here.

According to the instrumental reasoning argument, you can perfectly well reason from intentions that you have no reason to have, and from intentions that you think you have no reason to have. Therefore, according to the argument, the right account of instrumental rationality cannot have it that the norms of instrumental rationality are applicable only to intentions we have reason to have or only to intentions we think we have reason to have. The basic idea behind the argument is that the applicability of the norms of instrumental rationality should be expanded to accommodate instances of instrumental reasoning.

But the question I wish to pose is this: In terms of the challenge posed by the instrumental reasoning argument, are we any better off in looking at instrumental rationality as involving a restriction on a certain combination of 
intentions? It seems to me that we are not. If my analysis of Broome's position in the previous section is correct, then we can engage in instrumental reasoning (correctly or incorrectly) even when our intentions are consistent. Suppose I intend to buy a boat and believe borrowing money to be a necessary means. Whether or not I intend to borrow money-that is, whether or not my intentions are consistent - I can come to reason that the reasons against borrowing money also count against buying the boat and come to judge that I shouldn't buy the boat and maybe (if I'm not weak-willed) even come to intend not to buy the boat. My instrumental reasoning can proceed in exactly the same way whether or not my intentions are consistent. So, following the reasoning of the instrumental reasoning argument, the right account of instrumental rationality cannot have it that the norms of instrumental rationality are applicable only to inconsistent intentions. We need to expand our account of instrumental rationality to accommodate instances of instrumental reasoning that occur even when our intentions are consistent, just as Broome and Wallace pointed out that Korsgaard needed to expand her account of instrumental rationality to accommodate instances of instrumental reasoning that occur even when our intentions are unreasonable or thought to be unreasonable. One might worry that the above argument is problematic since I am using the term "instrumental reasoning" in a different sense from the way in which it is used by Broome. In the previous section, I drew a distinction between instrumental reasoning and intending as one judges one should intend. In my view, instrumental reasoning involves seeing the inferential connections between means and ends, such as seeing that if there is no reason to intend the necessary means, there is also no reason to intend the end. However, being properly motivated, such as actually abandoning an intention when one sees no reason to have it or forming one when one sees reason to have it, while part of instrumental rationality, does not involve instrumental reasoning. ${ }^{31}$ However, for Broome, instrumental reasoning is practical in the sense that it issues in an intention. Broome disagrees with Aristotle's claim that practical reasoning must issue in an action since an action also requires the presence of a physical ability. But he claims that "intending to act is as close to acting as reasoning alone can get us, so we should take practical reasoning to be reasoning that concludes in an intention." ${ }^{32}$ But even if we accept Broome's understanding of instrumental reasoning, I believe my argument above is still sound. I could concede that instrumental reasoning, if it is to be genuinely practical reasoning, must issue in an intention but deny that it must start from an intention. It could instead start from our beliefs about what we have reason to do, or our beliefs about which activities or pursuits are valuable. My point is that even when our intentions are weak-willed, our ability to engage in practical reasoning is not thereby limited since it is open to us to start a line of reasoning from these other sources and have that line of reasoning issue in an intention. 
For instance, a line of practical reasoning could have as its first premise "Borrowing money is something I have no reason to do" or, if it appealed to the reasons themselves, "Borrowing money would put me too far into debt, which is no good." The first premise need not be "I intend not to borrow money." Indeed, we often do not refer to our intentions when engaging in practical reasoning and we instead refer to the reasons themselves or the fact that the reasons suggest a certain course of action. Perhaps this is because we do not think that the conclusion of our reasoning - the resulting intention depends on whether or not we have the relevant intentions to start with. Specifically, we think that the correctness of our reasoning would not be vitiated by our being weak-willed in our initial intentions. For instance, when I reason from "Borrowing money will put me too far into debt, which is no good" and "Borrowing money is necessary to buy a boat" and conclude in the intention to not buy the boat, I do not think that this line of reasoning would in any way be rendered incorrect by my being weak-willed and not intending not to borrow money.

Broome finds fault in Korsgaard's account since practical reasoning need not start from intentions we have reason to have and Wallace finds fault in Korsgaard's account since practical reasoning need not start from intentions we think we have reason to have. Both critiques point to other sources from which practical reasoning can proceed - our unreasonable intentions and our intentions thought to be unreasonable. And they conclude from this that there is a defect in those accounts of instrumental rationality that limit the applicability of the norms of instrumental rationality to instances in which agents have intentions they have reason to have or to instances in which agents have intentions they think they have reason to have. But correct instrumental reasoning need not start from our actual intentions. It could instead start from what we think we have reason to intend or from what we value, and so forth. So, in cases where agents have consistent intentions due to at least one of these intentions being a weak-willed intention, an agent could nonetheless engage in instrumental reasoning, correctly or incorrectly, from other sources. So, by the same reasoning Broome and Wallace use against Korsgaard, there would be a defect in an account of instrumental rationality that limited the applicability of the norms of instrumental rationality to instances in which agents had inconsistent intentions.

In short, if we attempt to expand our account of instrumental rationality in order to take into account instances of instrumental reasoning, as both Broome and Wallace do in reaction to Korsgaard, it is not enough to present an account of instrumental rationality according to which it merely involves consistency in intention, since even when our intentions are consistent we could reason correctly (or incorrectly) from other sources.

What's the lesson of all of this? I would suggest that one lesson is that there is not a strong connection between instrumental reasoning and instru- 
mental rationality. Specifically, we shouldn't look to where and when correct instrumental reasoning is possible to determine how to formulate our conception of instrumental rationality. Correct instrumental reasoning involves a correct transition - a transition to an intention, if we follow Broome - but the transition could start from a number of places. It could start, as Wallace pointed out against Korsgaard, from our weak-willed intentions, or, as I mentioned above, from our beliefs about what is reasonable or valuable. (And one could fail in this transition, as I argued in section two, by either failing to understand the correct inferential relations or by failing in one's motivations.) But given that this transition could start from a number of places, we will not settle the matter of what our conception of instrumental rationality should be by looking at where and when this kind of successful transition can occur. If we follow Broome and think that instrumental rationality concerns a normative requirement - specifically a prohibition on a certain combination of intentions - we shouldn't think that this conception of instrumental rationality is supported by considerations of where and when correct instrumental reasoning is possible.

\section{Conclusion}

In summary, I have presented three objections to Wallace's attempt to account for the normativity of instrumental rationality in terms of the inconsistent beliefs held by the instrumentally irrational agent. I believe that Broome's account, according to which instrumental rationality involves a restriction on a certain combination of intentions, can avoid these three objections and is therefore a more promising account. But one problem with Broome's account is that the formation of the intention in (6), given an agent who has the intention in (4) and the belief in (5), does not suffice to make an agent instrumentally rational since this intention could be a weak-willed one and the agent could fail to see that the reasons against intending (6) are also reasons against intending (4). In other words, there is an available line of reasoning starting from the claim that there is no reason to intend (6) leading to the conclusion that there is no reason to intend (4) and one could fail to reason along these lines correctly. Even if we think, as Broome does, that instrumental reasoning, if it is to be genuinely practical reasoning, must issue in the agent ceasing to intend (4), there is still an available line of reasoning present. This is an important conclusion because it shows that Broome's approach of looking at instrumental rationality as involving a restriction on a certain combination of intentions is actually vulnerable to the instrumental reasoning argument which both Broome and Wallace present against different parts of Korsgaard's conception of instrumental rationality - Broome against Korsgaard's claim that we must have a reason to intend an end if there is to be a requirement to intend the means and Wallace against Kors- 
gaard's claim that we must think the fact that we will an end is a reason for the end. The instrumental reasoning argument points to available lines of instrumental reasoning and suggests that Korsgaard's account of instrumental rationality needs to expand to account for these available lines of reasoning. But an agent with consistent intentions could still engage in instrumental reasoning correctly or incorrectly from other sources, and so Broome's conception of instrumental rationality, according to which instrumental rationality involves a restriction on a certain combination of intentions, is also vulnerable to the instrumental reasoning argument.

In conclusion, of the two approaches to instrumental rationality as a restriction on a certain combination of attitudes (beliefs for Wallace and intentions and a belief for Broome) we should prefer Broome's approach. However, we should not think that Broome's approach to instrumental rationality tells the whole story of instrumental rationality since agents with consistent intentions could still fail in their instrumental reasoning. And we should also be aware that this makes Broome's account vulnerable to the line of criticism which both he and Wallace present against Korsgaard's conception of instrumental rationality. 
${ }^{1}$ R. Jay Wallace "Normativity, Commitment and Instrumental Reason" Pbilosopher's Imprint V.1, No.3, 2001.,www.philosophersimprint.org/001003.

${ }^{2}$ John Broome "Practical Reasoning" in Jose Bermudez, ed. Reason and Nature: Essays in the Theory of Rationality (Oxford: Oxford University Press, 2002). See also his companion pieces "Normative Requirements" in Jonathan Dancy, ed. Normativity (Oxford: Blackwell Publishers, 2000) and "Are Intentions Reasons? And How Should we Cope with Incommensurable Values?" in Christopher W. Morris and Arthur Ripstein, eds. Practical Rationality and Preference: Essays for David Gauthier (Cambridge: Cambridge University Press, 2001).

${ }^{3}$ Wallace "Normativity, Commitment and Instrumental Reason" p. 21.

${ }^{4}$ Ibid. p. 21.

${ }^{5}$ Ibid. p. 22.

${ }^{6}$ Michael Bratman "Intention and Means-End Reasoning" The Philosophical Review, XC, No. 2 (April 1981). pp. 252-265. See especially 259-260.

${ }^{7}$ Ibid. p. 260.

${ }^{8}$ Broome "Practical Reasoning" p. 87-90.

${ }^{9}$ Ibid. p. 87.

${ }^{10}$ Ibid. p. 88.

${ }^{11}$ Ibid. p. 88-90.

${ }^{12}$ Christine Korsgaard "The Normativity of Instrumental Rationality" in Garrett Cullity and Berys Gaut eds. Ethics and Practical Reason (Oxford: Clarendon Press, 1997) pp. 215-254. See. p. 238.

${ }^{13}$ Ibid. p. 238.

${ }^{14}$ T.M. Scanlon What We Owe to Each Other (Cambridge, Massachusetts: Belknap Press of Harvard University Press, 1998), p. 21. See also his "Reasons: A Puzzling Duality" in R. Jay Wallace, Philip Pettit, Samuel Scheffler, and Michael Smith, eds. Reason and Value: Themes from the Moral Philosophy of Joseph Raz: (Oxford: Clarendon Press, 2004) pp. 231-246.

15 Also, keep in mind that if you have a reason to do something, and no reason not to do it, then you ought to do it. So, if intentions were reasons, in some cases, intending the end makes it that you ought to do it. But, as both Broome and Wallace note, this is implausible since normativity cannot spring from nowhere in this manner.

${ }^{16}$ These arguments can be found in Broome's “Are Intentions Reasons? And How Should We Cope with Incommensurable Values?" pp. 98-100 and 105-107 and Wallace's "Normativity, Commitment and Instrumental Reason" pp. 14-17.

${ }^{17}$ This term, and this formulation of the problem, come from Michael Bratman's "Intention and Means-End Reasoning." Op. Cit.

${ }^{18}$ Broome "Normative Requirements" pp. 79-83.

${ }^{19}$ Ibid. pp. 83-90.

${ }^{20} \mathrm{Ibid}$. pp. $79-83$ and $97-98$. 
${ }^{21}$ Korsgaard "The Normativity of Instrumental Rationality" p. 220.

22 Ibid. p. 245.

${ }^{23}$ Ibid. p. 220.

24 Broome "Normative Requirements" p. 97.

25 Ibid. p. 98.

${ }^{26}$ Broome also presents this argument in his "Are Intentions Reasons? And How Should We Cope with Incommensurable Values?” pp. 110-111.

${ }^{27}$ Korsgaard “The Normativity of Instrumental Rationality” pp. 245-246.

28 Ibid. p. 246.

${ }^{29}$ Wallace "Normativity, Commitment and Instrumental Reason" p. 1.

${ }^{30}$ Ibid. pp. 16-17.

31 I also mentioned earlier that one might claim that being properly motivated is not part of instrumental rationality, strictly speaking, since it concerns the same motivational successes or failures that would be involved in setting ends. But I saw no reason to speak strictly and so I here include it within the realm of instrumental rationality, taking care to note that being properly motivated does not involve instrumental reasoning.

32 Broome "Practical Reasoning" p. 85. 